\title{
METODE
}

\section{NAVIDEZNA ZVRNJENOST OBJEKTOV NA DRŽAVNEM ORTOFOTU ALI KAJ MORAMO VEDETI, KO UPORABLJAMO DRŽAVNI ORTOFOTO?}

\author{
AVTORICA \\ dr. Mihaela Triglav Čekada \\ Geodetski inštitut Slovenije, Jamova 2, SI - 1000 Ljubljana, Slovenija \\ mihaela.triglav@gis.si
}

DOI: $10.3986 / G V 88107$

UDK: 528.7:551.43

COBISS: 1.01

\section{IZVLEČEK}

Navidezna zvrnjenost objektov na državnem ortofotu ali kaj moramo vedeti, ko uporabljamo državni ortofoto?

Državni ortofoto merila 1:5000, narejen na podlagi posnetkov Cikličnega aerofotografiranja Slovenije $(C A S)$ in digitalnega modela reliefa (DMR), je najbolj pogosto uporabljen vir za različne GIS analize in fotointerpretacijo. Na tem sloju prikazujemo tudi druge vektorske ali rasterske sloje, ki so lahko položajno tudi bolj natančni od ortofota. Uporabniki ortofota se večkrat ne zavedajo, da ima lahko ortofoto tudi položajne napake. V tem članku zato, preko geometrijskih povezav posnetka in prikaza ortofota, izpeljemo največjo zvrnjenost objektov, ki se nahajajo nad ali pod DMR-jem. Ugotavljamo, da zvrnjenost višjih objektov na ortofotu, kot so višje skalne stene (višina $50 \mathrm{~m}$ ), višje stavbe (na primer cerkveni zvoniki) in gozdni rob, lahko presega dovoljena položajna odstopanja ortofota, vsaj v skrajnih primerih, ko se ti objekti nahajajo blizu šiva med dvema posnetkoma. Pri ortofotih, narejenih s pomočjo brezpilotnih letalnikov, je problematika položajne točnosti še večja, saj za izdelavo ne uporabljamo DMR-jev enovite točnosti, kot pri izdelavi državnega ortofota.

\section{KLJUČNE BESEDE}

državni ortofoto, Ciklično aerofotografiranje Slovenije, digitalni modeli višin, položajna točnost, Slovenija

\begin{abstract}
Radial displacement of objects on the national orthophoto or what we should know when using national orthophoto?

The Slovenian national orthophoto in the scale 1:5,000 is made from the Cyclical Aerophotogrammetric Survey of Slovenia (CAS) images and the digital terrain model (DTM). It is the most widely used spatial source for a variety of GIS analyses and visual photointerpretation in Slovenia. Different vector or raster spatial layers can be shown on it, which may be even more precise than the orthophoto. The users of the orthophoto are often not aware, that orthophoto may include positional errors. Using the geometrical connection between the original image and the orthophoto we derive the maximal radial displacement expected on orthophoto for objects of different height above or below the DTM. We show that radial displacement of higher objects, like higher rocky cliffs (height $50 \mathrm{~m}$ ), tall buildings (like church towers) and forest edge, may exceed the permitted positional error of the orthophoto, at least in the extreme cases when these objects are located near the seam lines of the orthophoto. We also mention orthophotos made from images
\end{abstract}


of unmanned aerial vehicles (drones), where the problem of its positional accuracy is even broader, as for their production the DTM with nonuniform vertical accuracy is used.

\section{KEY WORDS}

national orthophoto, Cyclical Aerophotogrammetrical Survey, digital elevation models, spatial accuracy, Slovenia

Uredništvo je prispevek prejelo 15. junija 2016. 


\section{Uvod}

Vse prepogosto uporabniki prostorskih podatkov slepo verjamejo v absolutno položajno točnost lokacij objektov, ki so prikazani na državnih ortofotih Cikličnega aerofotografiranja Slovenije (CAS) ter položajno točnost celo zamenjujejo z njihovo prostorsko ločljivostjo (Kosmatin Fras s sodelavci 2006; Petrovič s sodelavci 2011). Ortofote ponekod še vedno imenujejo digitalni ortofoto (DOF), a ker jih v Sloveniji že več kot desetletje izdelujemo le $\mathrm{z}$ digitalnim postopkom izdelave, lahko pridevnik »digitalni« tudi opustimo.

Odstopanja na ortofotu zaznamo, ko na njem prikažemo druge vektorske ali rastrske sloje. Problem nastane predvsem ob hkratni uporabi več podatkovnih virov za zajem, na primer ortofoto in laserske podobe analitičnega senčenja DMR1. Kaj narediti, ko zaznamo položajna odstopanja večja od $1 \mathrm{~m}$ med dvema viroma? Ali res ortofoto vedno prikazuje najbolj točno lego? Odgovor na to je negativen, saj je ortofoto izdelek, ki je nastal iz posnetkov CAS in je »obremenjen « $\mathrm{z}$ napakami, pridobljenimi v postopku izdelave.

Namen tega članka je na pregleden in enostaven način predstaviti najbolj pomembne značilnosti podatkov državnega ortofota CAS ter podati ocene, ki nam lahko pomagajo izračunati, kako velika so položajna odstopanja ortofota od prave lege in še ne predstavljajo grobih napak ortofota. Teh dovoljenih odstopanj se moramo ob uporabi ortofota zavedati. Omenili bomo tudi ortofote, narejene s pomočjo brezpilotnih letalnikov, kjer so prostorske ločljivosti sicer veliko večje, položajne točnosti lokacij na ortofotu pa veliko bolj nehomogene.

\section{Postopek izdelave državnega ortofota}

Med fotogrametričnim snemanjem velikega formata Cikličnega aerofotografiranja Slovenije dobimo zaporedne posnetke površja v centralni projekciji. Zaporedne posnetke ene snemalne linije imenujemo stereoposnetki, dva zaporedna posnetka pa tvorita stereopar. Zaporedni posnetki se med sabo prekrivajo, temu pravimo vzdolžni preklop posnetkov (angleško overlap). Posnetki se prekrivajo tudi s spodnjo ali zgornjo snemalno linijo, čemur pravimo prečni preklop (side overlap). Do leta 2014 je bil zahtevan vzdolžni preklop $60 \%$ in prečni $20 \%$, s CAS 2015 pa je vzdolžni $80 \%$ in prečni $30 \%$ (Razpisna ... 2008; 2014; 2015). Na delu posnetkov, kjer se dva stereoposnetka prekrivata, prikazujeta isto območje, ter tvorita stereomodel, ki omogoča stereoskopsko 3R-izmero objektov. Stereoskopsko izmero izvajamo na fotogrametričnih postajah, to so računalniki s posebno programsko in strojno opremo, ki omogoča stereoskopsko gledanje. Slovenija že ima večletno tradicijo izdelovanja programskih orodij za stereofotogrametrično izvrednotenje (Triglav Čekada s sodelavci 2016).

Ortofoto je fotogrametrični izdelek, ki ga dobimo s transformacijo enega posnetka iz centralne projekcije v ortogonalno projekcijo (Kraus 2004; Kosmatin Fras 2004). Ortogonalna projekcija omogoči, da je celotno območje predstavljeno v enotnem merilu, kar nam na ortofotih omogoča 2R-izmero. Ortofoto ne omogoča 3R-izmere.

Za izdelavo ortofota potrebujemo poznano notranjo in zunanjo orientacijo posnetka ter digitalni model višin (DMV) območja, ki je prikazano na posnetku. Notranja orientacija posnetka (internal orientation) podaja lokacijo projekcijskega centra na samem posnetku v slikovnem koordinatnem sistemu ter različne distorzije posnetka. Zunanja orientacija posnetka (external orientation) pa podaja lokacijo projekcijskega centra v globalnem koordinatnem sistemu (PC na sliki 2), v primeru državnega ortofota je to od CAS 2009 naprej koordinatni sistem D96/TM. Za izdelavo ortofota lahko uporabimo različne DMV-je (sliki 1 in 2): v kolikor uporabimo digitalni model reliefa (DMR) (digital terrain model), ki opisuje tla pod objekti, dobimo navadni ortofoto oziroma kratko ortofoto, kjer se streha višje stavbe ne nahaja nad temelji te stavbe ter so vrhovi dreves na gozdnem robu zvrnjeni (sliki 2a in 3a). V kolikor uporabimo digitalni model površja (DMP) (digital surface model), ki opisuje ploskev, ki pokriva 
vrhove objektov (prikazuje vrhove dreves in vrhove hiš), dobimo pravi ortofoto (true orthophoto), kjer strehe stavb pokrivajo temelje stavb (sliki $2 \mathrm{~b}$ in $3 \mathrm{~b}$ ). Za izdelavo pravega ortofota pa ni dovolj le uporaba DMP, temveč morajo posnetki imeti tudi veliko večji vzdolžni in prečni preklop, da lahko zapolnimo vso vsebino pod navidezno nagnjenimi stavbami.

Pri izdelavi državnega ortofota uporabimo DMR, zato lokacije streh na njem niso na pravem mestu. Da zmanjšamo odstopanja, ki so največja na zunanjih robovih originalnega posnetka, vzamemo $\mathrm{v}$ postopek transformacije le najbolj osrednji del posnetka in po naravnih linijah (na primer po robovih travnikov ali gozda) združujemo več ortofotov osrednjih delov posnetkov v skupni ortofoto, tako
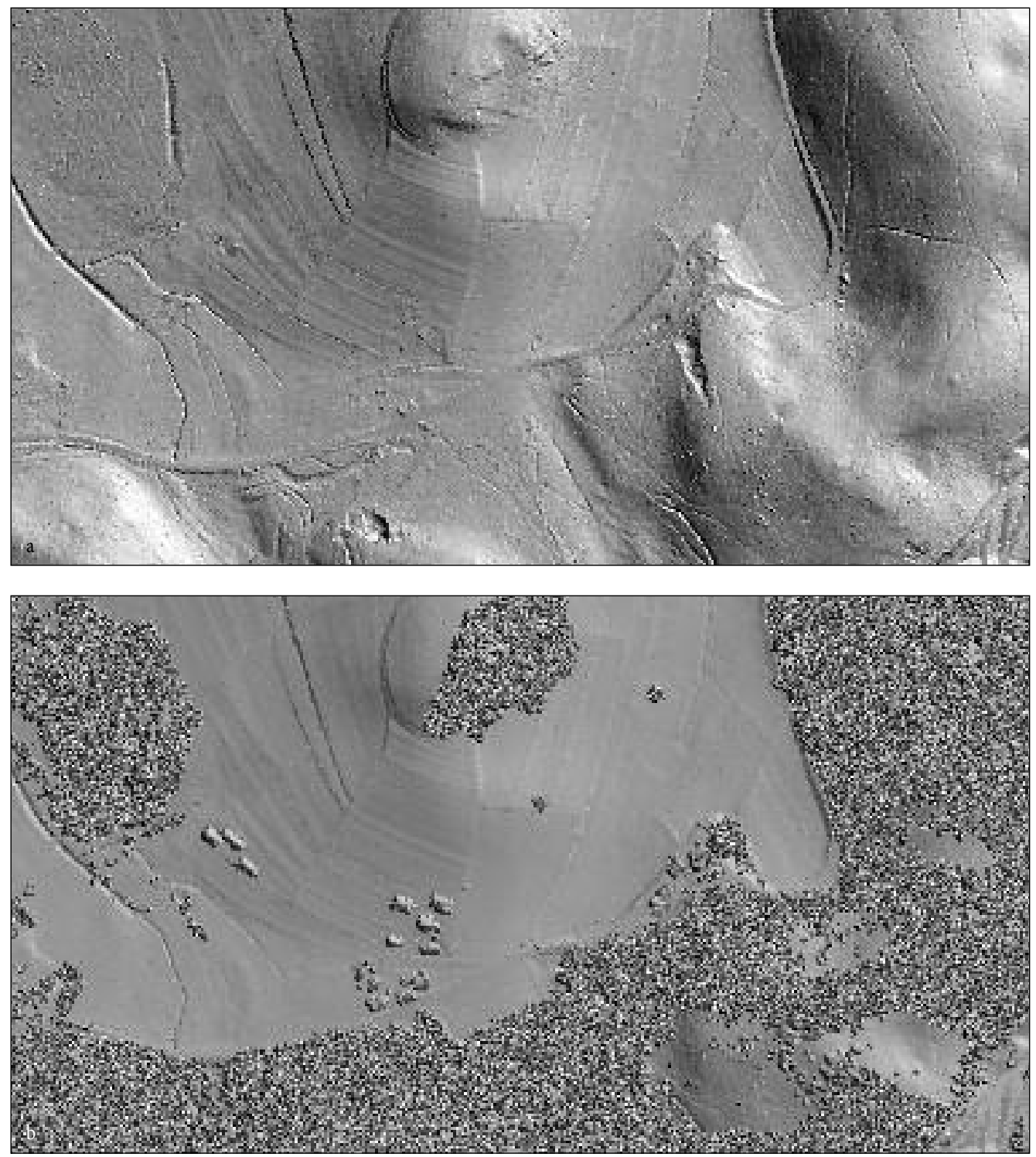

Slika 1: Digitalni modeli višin: (a) digitalni model reliefa (DMR) in (b) digitalni model površja (DMP). 


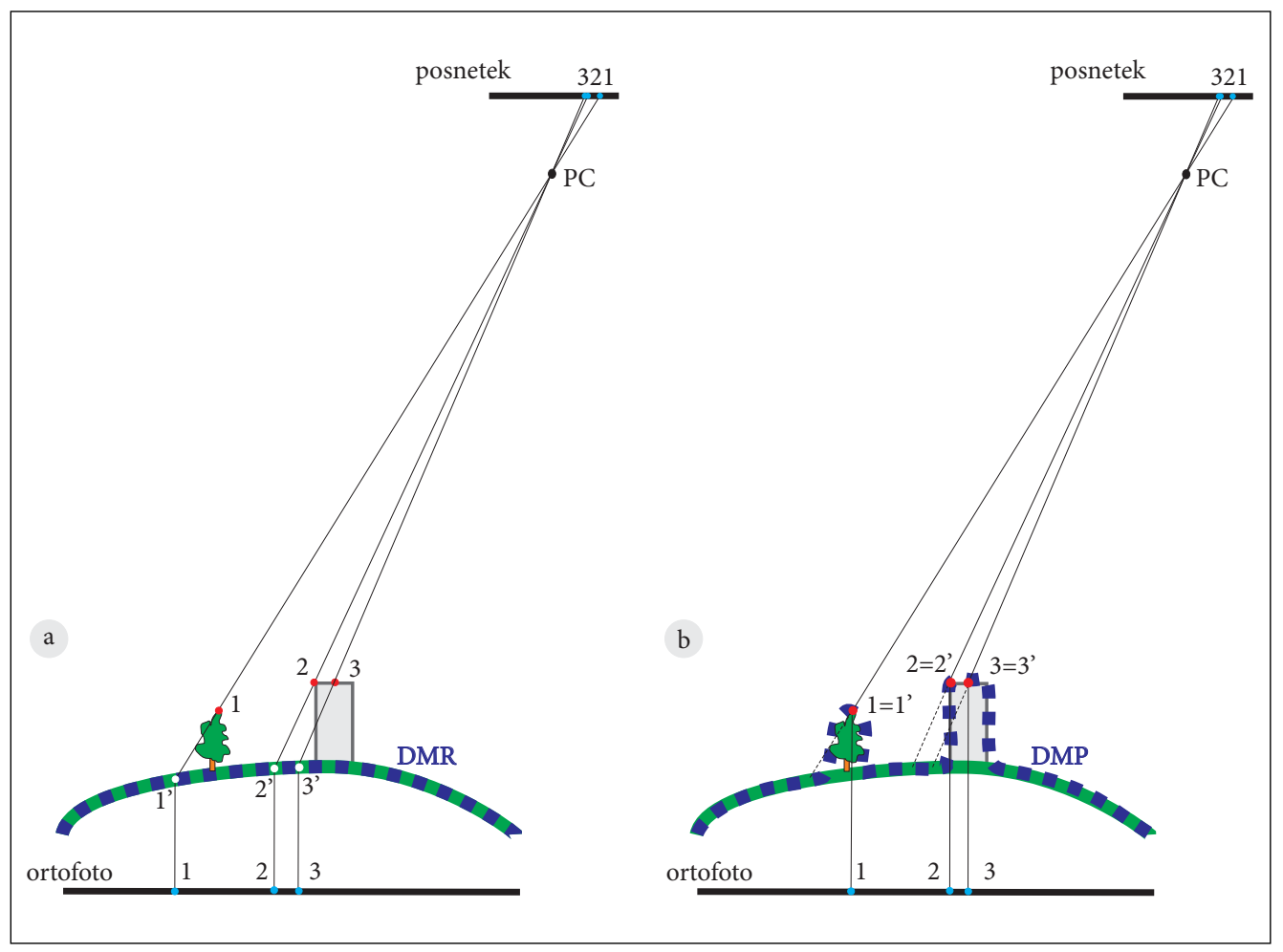

Slika 2: Shematični prikaz izdelave ortofota: (a) ob uporabi digitalnega modela reliefa (DMR) dobimo navadni (na primer državni ortofoto), (b) ob uporabi digitalnega model površja (DMP) pa pravi ortofoto.
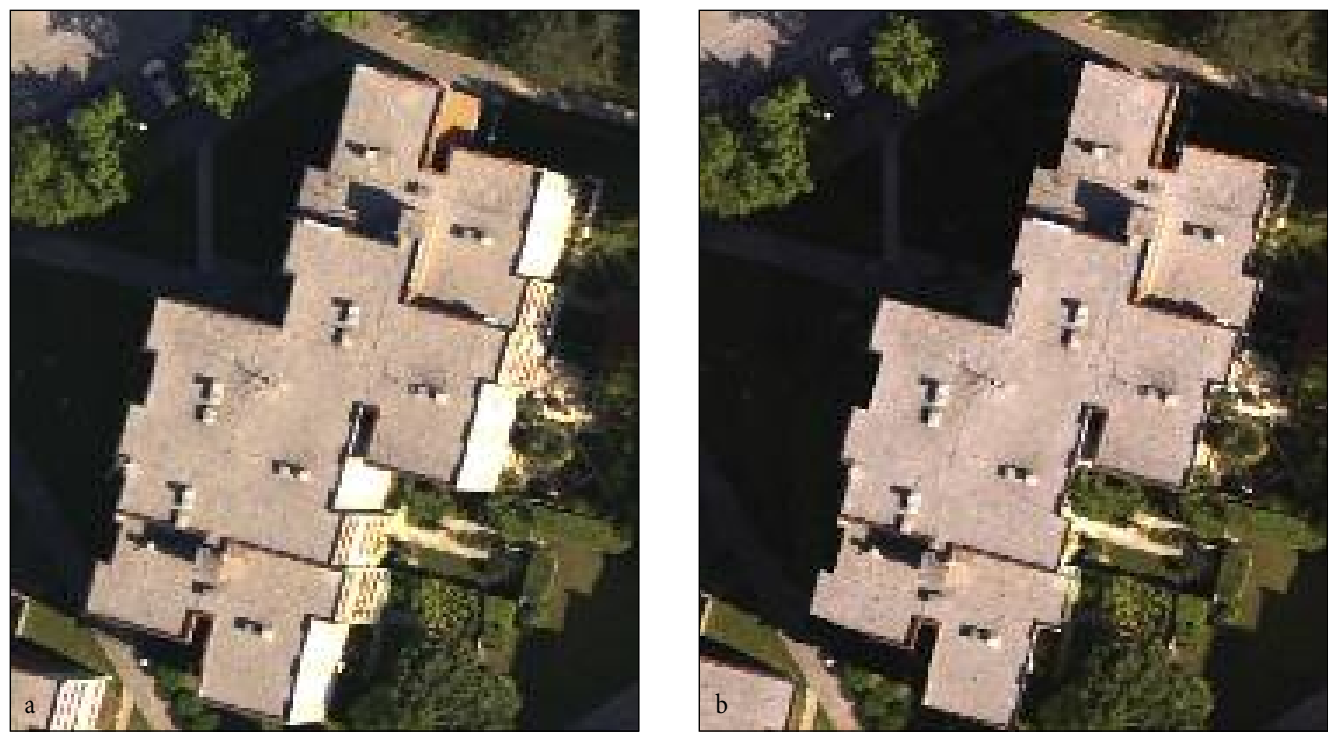

Slika 3: Navadni (a) in pravi ortofoto (b). 


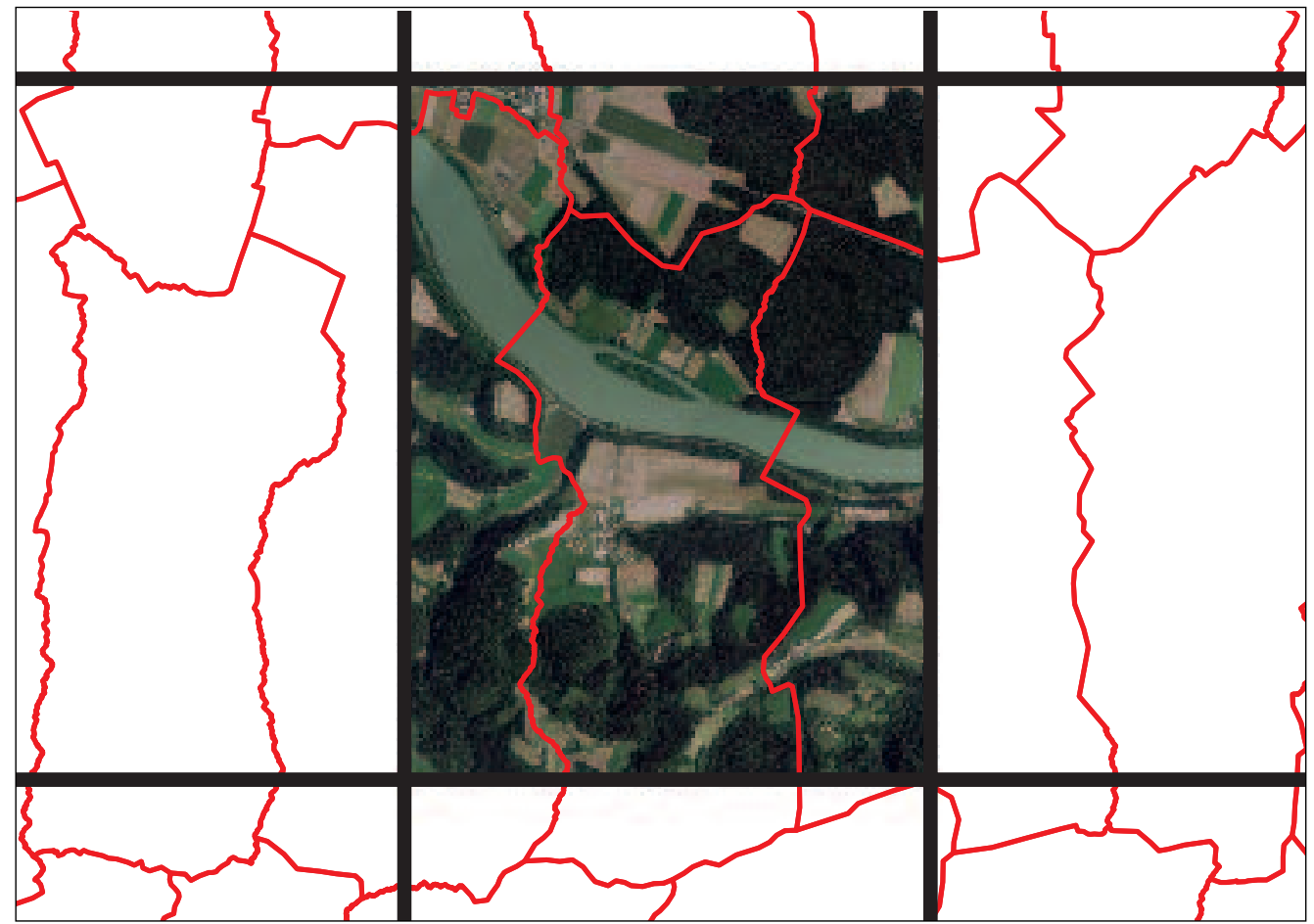

Slika 4: Šivne linije za sestavo enega ortofota (rdeče črte). Vsak sklenjen poligon predstavlja vsebino enega posnetka.

da zapolnimo območje ene karte merila 1:5000 (slika 4). Temu rečemo tudi mozaičenje končnega ortofota. Na stikih dveh delnih ortofotov se izvede izenačitev kontrasta in barv delnih ortofotov, zato da uporabnik v najboljšem primeru šivov (seam lines) niti ne opazi. Ob nerodni izbiri šivnih linij lahko na primer dobimo tudi presekane žice visokih elektrovodov.

S pomočjo sheme na sliki 2 opišimo postopek izdelave ortofota. Razlaga je povzeta in prirejena po Krausu $(2004,382)$. Skozi vsako točko na posnetku (na primer točka 3 na strehi stavbe) lahko rekonstruiramo premico, ki povezuje točko na posnetku, projekcijski center fotoaparata (PC) in objektno točko na tleh (3). Tej premici pravimo žarek. V kolikor uporabimo le en posnetek, vemo, da objektna točka leži nekje na tem žarku, njen točen položaj na terenu pa lahko pridobimo le tako, da uporabimo DMV (DMR ali DMP). Koordinata objektne točke na tleh se nahaja tam, kjer ta žarek seka DMV. Ortofoto dobimo tako, da tej objektni točki oziroma lokaciji objektne točke na DMV-ju pripišemo še barvo slikovnega elementa iz posnetka. V kolikor uporabimo DMR (sliki 2a), kot v primeru izdelave državnega ortofota, se točka na strehi stavbe preslika na nepravo mesto na DMR-ju (3'), saj točka presečišča žarka z DMR-jem ni enaka točki na objektu $\left(3 \neq 3^{\prime}\right)$, torej dobimo na ortofotu navidezno zvrnjeno streho stavbe (3) (radial displacement). V kolikor pa vzamemo za izdelavo ortofota DMP (slika 2b), se točka na strehi stavbe (3) preslika na pravo mesto, torej pravokotno nad temelj stavbe, saj je točka presečišča žarka z DMP enaka točki na objektu $\left(3=3^{\prime}\right)$. Na mestu, ki ga je v primeru slike 2a zapolnila napačno locirana streha stavbe (navidezno zvrnjena stavba), dobimo sedaj luknjo. To luknjo moramo zapolniti $\mathrm{z}$ vsebino iz drugega posnetka. Enako razliko vidimo še na primeru vrha drevesa, točka 1 . V primeru uporabe DMR-ja je drevo na ortofotu navidezno zvrnjeno, v primeru uporabe DMP-ja pa se nahaja približno nad deblom drevesa. 

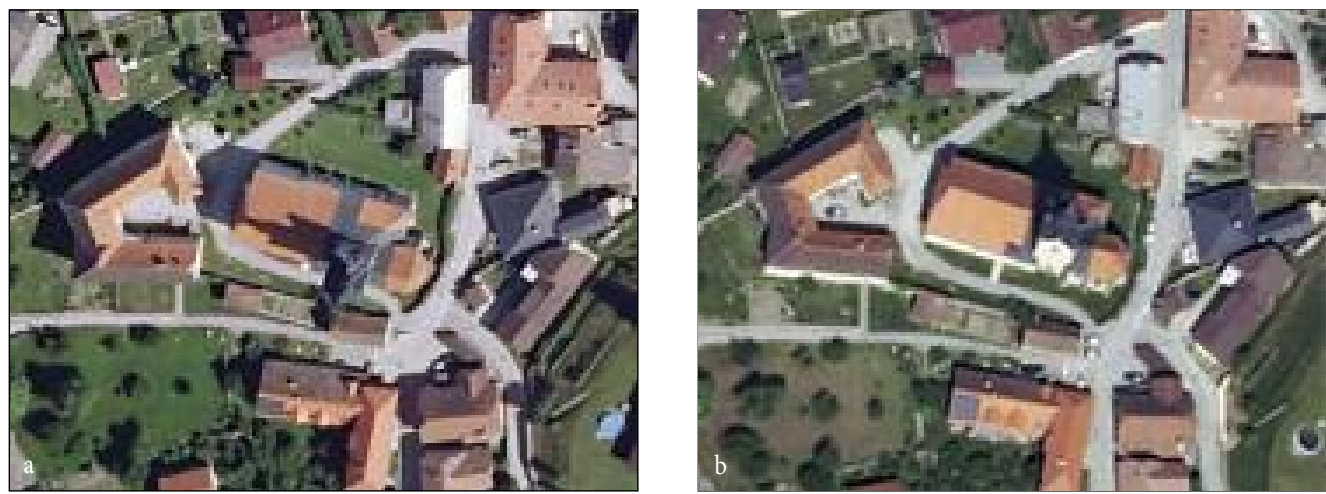

Slika 5: Nagib cerkvenega zvonika na dveh zaporednih državnih ortofotih iz leta 2013 (a) in leta 2014 (b).

$\mathrm{Na}$ dveh zaporednih CAS ortofotih so vsi visoki objekti, ki prikazujejo iste objekte, navidezno zvrnjeni v dve različni smeri (slika 5). V kolikor bi na zaporednih snemanjih CAS uporabljali vedno iste projekcijske centre (na istih lokacijah v prostoru), isti fotoaparat (z isto goriščno razdajo) in iste šivne linije pri mozaičenju ortofota, bi bil isti objekt iz dveh zaporednih CAS vedno zvrnjen v isto smer. Ker pa temu ni tako, saj snemanje vsakokrat izvaja drug izvajalec, so objekti navidezno zvrnjeni v dve različni smeri in tudi dolžina projekcije objekta na ortofotu je vsakokrat druga. Zvrnjenost najlepše vidimo na primeru cerkvenega zvonika $v$ osrednjem delu slike 5; pojav lahko opazimo tudi na sami ladji cerkve, saj enkrat vidimo njeno severno (slika 5a), drugič pa južno fasado (slika 5b).

\section{Opis kakovosti državnega ortofota}

Uporabnost ortofota za različne namene je odvisna predvsem od naslednjih značilnosti (Kosmatin Fras 2004; Kosmatin Fras, Fabiani in Triglav Čekada 2014):

- položajne točnosti objektov, predstavljenih na ortofotu oziroma geometrične točnosti georeferenciranja,

- prostorske ločljivosti, ki je opisana z dolžino talnega intervala, ki ga pokriva en slikovni element v naravi (ground sampling distance),

- semantične kakovosti ortofota: barvna globina, kontrastnost, ostrina, število barvnih kanalov,

- starosti ortofota oziroma aeroposnetkov (časovna ločljivost), ki smo jih uporabili za izdelavo ortofota.

Položajna točnost ortofota je odvisna od kakovosti parametrov zunanje in notranje orientacije posnetka ter kakovosti uporabljenega DMV-ja. Kakovost parametrov zunanje orientacije je pri državnem ortofotu odvisna od kakovosti izvedene aerotriangulacije, pa tudi od kakovosti realizacije samega koordinatnega sistema (Bric s sodelavci 2015). Od začetkov sistemske izdelave državnih ortofotov leta 1999 se položajna točnost ortofota vseskozi izboljšuje, zaradi uporabe vse natančnejših vhodnih podatkov za njihovo izdelavo. Največji preskok, povezan s položajno točnost in semantično kakovostjo, je prineslo leto 2006, ko se je za idelavo CAS začel uporabljati digitalni aerofotoaparat, izdelan pa je bil tudi nov fotogrametrični DMR z velikostjo celice $5 \mathrm{~m} \times 5 \mathrm{~m}$ (DMR5). Ta je nadomestil prej uporabljeni DMR25, ki je bil narejen sproti iz vsakokratnih posnetkov CAS. Leta 2009 se je začela izdelava izdelkov CAS v novem koordinatnem sistemu D96/TM, kar je prineslo izboljšanje točnosti izmere oslonilnih točk in izračuna projekcijskih centrov v postopku aerotriangulacije (Kosmatin Fras, Fabiani in Triglav Čekada 2014). Leta 2015 se je v postopek izdelave ortofota vpeljalo lidarski DMR $1 \mathrm{~m} \times 1 \mathrm{~m}$, kar bo ponovno prineslo pozitiven vpliv na položajno točnost ortofota. Za DMR5, ki je bil v uporabi za izdelavo ortofota med letoma 2006 in 2014, je največja dovoljena vrednost korena srednjega kvadratnega pogreška (RMSE - root mean square error) višin $1 \mathrm{~m}$ na odprtem in $3 \mathrm{~m}$ na poraščenem terenu (Kosmatin 
Fras, Fabiani in Triglav Čekada 2014). Za lidarski DMR1 pa je RMSE $15 \mathrm{~cm}$. Lidarsko snemanje Slovenije je bilo opravljeno za dve manjši območji leta 2011, večji del pa leta 2014 ter spomladi 2015 (Triglav Čekada in Bric 2015). Ker je zato DMR1 ponekod že zastarel, se ga mora pred uporabo za izdelavo ortofota preveriti in popraviti na območjih večjih sprememb. Zato je zahtevana višinska točnost uporabljenega DMR1 za izdelavo ortofota slabša: na odprtem $0,4 \mathrm{~m}$ in $1,2 \mathrm{~m}$ na poraščenem terenu (Razpisna ... 2015; 2016).

Ko imamo točnost podano z RMSE, se moramo zavedati, da lahko pričakujemo okoli dve tretjini odstopanj manjših od RMSE, za največja še dovoljena odstopanja pa običajno vzamemo trikratnik vrednosti RMSE (Pukelsheim 1994). Največja višinska odstopanja na poraščenem terenu na DMR5 lahko torej znašajo tudi $9 \mathrm{~m}$ in so še vedno znotraj dovoljenih odstopanj. V primeru DMR1, uporabljenega za izdelavo ortofota, pa so največja še dovoljena višinska odstopanja 3,6 m.

Prostorska ločljivost je odvisna od tehničnih lastnosti aerofotografiranja, torej od merila snemanja, ki je odvisno od višine leta nad površjem, goriščne razdalje ter velikosti slikovnega elementa na samem senzorju aerofotoaparata. Opišemo jo z dolžino talnega intervala, ki ga predstavlja en slikovni element v naravi. Državni ortofoti iz leta 2006 so imeli prostorsko ločljivost $0,5 \mathrm{~m}$ (RGB) ter ločen ortofoto, ki je prikazoval podatke tudi v bližnji infrardeči svetlobi z ločljivostjo $1 \mathrm{~m}$ (Petrovič s sodelavci 2011). Državni ortofoti iz CAS snemanj med letoma 2009 in 2014 pa so bili izdelani v dveh ločljivostih: 0,5 metra za večino države in $0,25 \mathrm{~m}$ za večja urbana območja (Kosmatin Fras, Fabiani in Triglav Čekada 2014). Izdelava ortofota v dveh ločljivostih za najbolj urbana območja se je nadaljevala tudi v sledečih razpisih. Leta 2015 sta bila izdelana dva bloka, ki sta v celoti pokrita z ločljivostima $0,5 \mathrm{~m}$ in $0,25 \mathrm{~m}$. S CAS 2012 dobimo ponovno tudi ortofoto $\mathrm{v}$ bližji infrardeči svetlobi z ločljivostjo $0,5 \mathrm{~m}$, ki sledi tudi v vseh nadaljnjih snemanjih (Razpisna ... 2011; 2014; 2015; 2016).

Semantična kakovost ortofota je odvisna od lastnosti aerofotoaparata ter od dela dneva, ob katerem je dovoljeno snemanje. Pri državnem ortofotu je snemanje dovoljeno v času optimalne svetlobe, ko so sence kratke ter so ustrezne vremenske razmere (na primer ni megle, koprenaste oblačnosti, snega). V razpisni dokumentaciji je bil pred letom 2015 dovoljen čas snemanja opredeljen s kotom višine sonca, ki ne sme biti nižji od $40^{\circ}$ nad horizontom. Po tem letu je ta pogoj rahko omiljen; odtlej kot višine sonca ne sme biti nižji od $30^{\circ}$. Državni ortofoto se ponavadi snema v času zalistanosti, to je večinoma poletji oziroma približno od sredine aprila do avgusta (Razpisna ... 2009; 2011; 2014; 2015; 2016), saj je namenjen tudi vsakoletnemu spremljanju dejanske rabe kmetijskih zemljišč (Opis ... 2016).

Časovna ločljivost ortofotov je enaka ciklu CAS. Že od leta 1985 se CAS snema tako, da se v treh letih posname celotno Slovenijo. Ortofoti so se za posamezna območja začeli izdelovati okoli leta 1995, leta 1999 pa se je začela njihova sistemska izdelava, torej pokritje celotne Slovenije z ortofoti v enem ciklu CAS (Kosmatin Fras, Fabiani in Triglav Čekada 2014). Izjemi sta le presečni leti 2006 in 2014, ko je bila celotna Slovenija posneta v enem letu. Žal presečno leto 2014 ni bilo popolno, saj sta v njem izpadla dva fotogrametrična bloka, ki pokrivata Alpe. Ta dva bloka sta bila posneta naknadno (leta 2015) z novimi razpisnimi pogoji, ki so že vključevali uporabo lidarskega DMR1 za izdelavo ortofota (Razpisna ... 2015). Leta 2016 se je začel nov cikel CAS, ki naj bi v letu 2016 pokril vzhodni del Slovenije (Razpisna ... 2016).

\subsection{Deklarirana položajna točnost ortofota}

V razpisni dokumentaciji CAS, kjer je opredeljen tudi izdelek ortofoto, je opredeljena položajna točnost ortofota med letoma 2009 in 2014 1,0 m RMSE (Kosmatin Fras, Fabiani in Triglav Čekada 2014). Leta 2015 se je opredeljena položajna točnost zaradi uporabe DMR1 izboljšala na $0,75 \mathrm{~m}$, (Razpisna ... 2015). Kot smo že omenili, so največja še dovoljena odstopanja trikratnik RMSE, torej če na ortofotu $\mathrm{z}$ vključno letom 2014 najdemo odstopanje veliko $3 \mathrm{~m}$ oziroma leta 2015 odstopanje $2,25 \mathrm{~m}$, to še ne kaže na grobo napako. Ta odstopanja so predpisana za kontrolne točke, ki se nahajajo na tleh.

Vrhovi visokih stavb in visoko rastje (rob gozda) so lahko veliko bolj navidezno zamaknjeni oziroma zvrnjeni, kar bomo pokazali v nadaljevanju. Dodatne napake v položaju lahko pričakujemo tudi 
zaradi same ločljivosti DMR, predvsem ko je bil ortofoto izdelan še s pomočjo DMR5 (vse do leta 2014). Sama celica DMR5 je velika $5 \mathrm{~m} \times 5 \mathrm{~m}$ in lahko zgladi majhne in ozke skoke v višini. To so na primer ozke in globoke struge potokov, ožje od dolžine celice DMR5, ter pragovi na vodotokih. Pri uporabi DMR1 za izdelavo ortofota je teh zglajevanj manj, vendar kljub temu ne moremo reči, da jih ni. Omenimo le nezglajeni DMR1 na večjih ploskvah vod, kjer pride do nepravilnih višinskih skokov v višini gladine vode. Ti skoki so nastali zaradi premajhnega števila laserskih točk, ki so se odbile od vodne gladine in se jih je uporabilo v procesu avtomatske interpolacije DMR1. Skokov v višini gladine vod se ročno ni popravljalo, da ne bi nehote zbrisali kaj bistvenega na robovih vod, saj je bil lidar prvenstveno namenjen zajemu vodnih površin (Triglav Čekada in Bric 2015). Prav tako DMR1 in DMR5 nista popolnoma točna v visokogorju, kjer že majhna razlika v položaju točke DMR, lahko pomeni velike razlike v višini te točke predvsem na prepadnih gorskih stenah.

\subsection{Izračun potencialnih položajnih odstopanj}

Potencialna položajna odstopanja bomo izračunali s pomočjo slike 6, na kateri so prikazana temeljna geometrijska razmerja med skoraj navpičnim posnetkom in preslikavo posnetka na tla (razlaga je prirejena po Krausu 2004, 377). Za posnetke CAS zgornji pogoj o skorajšnji navpičnosti drži, saj je za njih zahtevano, da imajo zelo majhne naklone glede na vodoravno lego (na primer Razpisna ... 2008). Za posnetke letalnikov, ki jih bomo obravnavali v nadaljevanju, pa tega ne moremo reči (poglavje 4).

Pri izvajanju si bomo pomagali s pravimi podatki iz različnih CAS snemanj, izvedenimi po letu 2009, ki jih lahko najdemo v tehničnih poročilih aerofotografiranj, izdelavi ortofotov ali v kalibracijskih poročilih uporabljenih aerofotoaparatov. Že v razpisni dokumentaciji CAS je podana osnovna ločljivost posnetkov kot dolžina talnega intervala $0,25 \mathrm{~m}$ (DTI - ground sampling distance), ki se preslika v en slikovni element originalnega posnetka (stranica piksla $-d$ ). Velikost senzorja v slikovnih elementih (image format ali number of rows/columns), velikost samega slikovnega elementa (pixel size) ter goriščna razdalja (focal length) so podani v kalibracijskem poročilu fotoaparata (primera v preglednici 1).

Preglednica 1: Primera osnovnih parametrov dveh digitalnih aerofotoaparatov uporabljenih $v$ projektu CAS med letoma 2009 in 2014 (podatki so povzeti po kalibracijskih poročilih).

\begin{tabular}{lcc} 
parameter & Vexcel UltraCam-XP & UltraCamEagle \\
\hline velikost senzorja (v slikovnih elementih) & $11.310 \times 17.310$ & $13.080 \times 17.310$ \\
velikost enega slikovnega elementa & $6 \mu \mathrm{m} \times 6 \mu \mathrm{m}$ & $5,2 \mu \mathrm{m} \times 5,2 \mu \mathrm{m}$ \\
goriščna razdalja & $100,500 \mathrm{~mm}$ & $79,800 \mathrm{~mm}$
\end{tabular}

Na sliki 6 (v podnapisu k sliki so razložene okrajšave za spodnje izraze) vidimo, da dolžino slikovnega elementa $d$ in dolžino talnega intervala DTI povezuje naslednji izraz (1):

$$
\frac{d}{f}=\frac{D T I}{Z_{0}}
$$

Višino izbokline $\Delta Z$ in projekcijo te izbokline na tla $\Delta R$ povezuje (2):

$$
\frac{\Delta R}{R}=\frac{\Delta Z}{Z_{0}} \text { ali } \Delta R=\frac{\Delta Z}{Z_{0}} \cdot R
$$

Povežemo lahko tudi projekcijo izbokline na tla $\Delta R$ s projekcijo izbokline na posneteku $\Delta p(3)$ :

$$
\frac{\Delta p}{f}=\frac{\Delta R}{Z_{0}}
$$




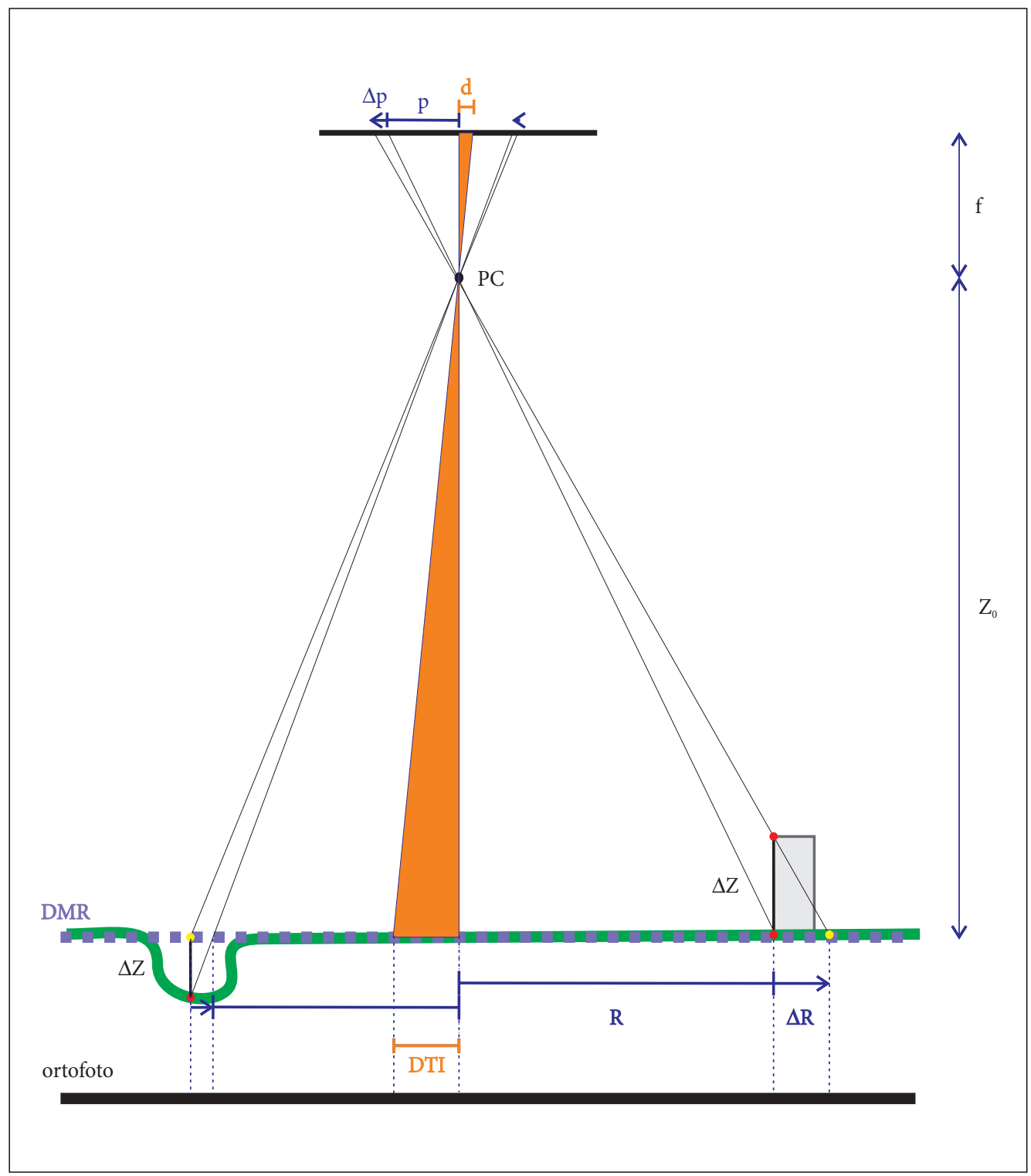

Slika 6: Shematični prikaz, kako višina izbokline (hiše) ali vbokline (jarek) vpliva na navidezno zvrnjenost objekta na ortofotu (PC - projekcijski center aerofotoaparata; $\Delta R$ - navidezna zvrnjenost objekta na ortofotu oziroma dolžina preslikave objekta na teren, če bi sonce sijalo iz projekcijskega centra; $R$ - oddaljenost med projekcijo projekcijskega centra na teren in točko, v kateri se nahaja visoki objekt; $\Delta Z$ - višina visokega objekta nad DMR ali globina luknje pod DMR; $Z_{0}$ - višina leta nosilca aerofotografiranja; $f$-goriščna razdalja objektiva aerofotoaparata; $\Delta p$ - dolžina preslikave objekta na posnetku; $p$-oddaljenost med projekcijo projekcijskega centra na posnetek in točko temelja visokega objekta na posnetku; DTI - dolžina talnega intervala preslikave enega slikovnega elementa na teren; $d$ - dolžina slikovnega elementa na posnetku). 
S pomočjo podatkov v prvem stolpcu preglednice 1, ki opisuje fotoaparat Vexcel UltraCam-XP in izraza (1), lahko izračunamo višino leta nad tlemi $Z_{0}$. Ob dolžini talnega intervala $D T I=0,25 \mathrm{~m}$, dobimo višino leta približno $Z_{0}=4190 \mathrm{~m}$. Da bomo dobili največjo mogočo razdaljo $R$, kjer še uporabljamo podatke enega posnetka, si pomagamo s skico šivnih linij na ortofotu (slika 4 - primer iz CAS 2014). Ker je ortofoto merila 1:5000 v naravi dimenzij $2250 \mathrm{~m} \times 3000 \mathrm{~m}$, je povprečni osrednji del ortofota, ki ga uporabimo pri mozaičenju širok $1200 \mathrm{~m}$ in visok $2200 \mathrm{~m}$. Ker je projekcijski center v sredini te razdalje, je največja razdalja $R$ lahko le polovica teh vrednosti, torej $600 \mathrm{~m}$ ali $1100 \mathrm{~m}$.

Sedaj pa si lahko poljubno izberemo višino objekta, ki gleda nad DMR ali je skrit pod DMR, in izračunamo največjo navidezno zvrnjenost takšnega objekta na ortofotu $\Delta R$ ali na posnetku $\Delta p$ (uporabimo izraz (3)). Rezultati tipičnih primerov so podani v preglednici 2. Objekti si sledijo padajoče glede na višino. Med rezultati so odebeljeno izpisani primeri, ki še ne presegajo trikratnika RMSE za ortofoto od leta 2015 naprej $(\mathrm{RMSE}=0,75 \mathrm{~m}$ ). Največje napake lahko pričakujemo $\mathrm{v}$ visokogorju, predvsem na previsnih stenah, kjer majhna napaka $\mathrm{v}$ položaju točke DMR hitro prinese veliko napako v višini. Največje odstopanje $50 \mathrm{~m}$ visoke stene v tem primeru znese več kot $13 \mathrm{~m}$, kar je 52 slikovnih elementov na ortofotu z DTI $0,25 \mathrm{~m}$. Takšna navidezna zvrnjenost močno presega trikratnik dovoljenega položajnega RMSE za ortofoto. Tudi višji cerkeni zvoniki višine $20 \mathrm{~m}$ presegajo dovoljeni trikratnik položajnega odstopanja ortofota. Rob mešanega gozda z različno starimi drevesi višine $10 \mathrm{~m}$ lahko dovoljeno odstopanje presega v najširšem delu ortofota, v najožjem delu pa je še znotraj dovoljenega. Dvoetažne družinske hiše so znotraj dovoljenih odstopanj v obeh primerih. Ker pa so stavbe v mestih večinoma višje od dvoetažnih hiš, lahko predvsem v strnjenih mestnih naseljih na ortofotu pričakujemo mnogo preveč zvrnjenih stavb, v kolikor šivanje ortofota ni bilo izvedeno optimalno.

$\mathrm{Na}$ dnu preglednice 2 sta podani še dovoljeni odstopanji zaradi napak DMR, torej trikratnik višinske napake RMSE. V kolikor bi pri izdelavi ortofota 2015 uporabili star DMR5, bi na njem velikokrat našli položajna odstopanja, ki presegajo trikratnik dovoljenih odstopanj. V kolikor uporabimo DMR1 in sklepamo, da je ta vsepovsod tako natančen, kot je predpisano, pa bi morala biti položajna odstopanja znotraj dovoljenih odstopanj. Obstaja pa velika verjetnost, da DMR1 vsaj na previsnih stenah visokogorja ni tako natančen, kot je predpisano.

Preglednica 2: Največje pričakovane dolžine zvrnjenosti objektov na državnem ortofotu.

objekt

$\Delta Z$

zvrnjenost na ortofotu $\Delta R(\mathrm{~m})$

$R=600 \mathrm{~m} \quad R=1100 \mathrm{~m}$

navpična gorska stena

cerkveni zvonik

rob mešanega gozda $\mathrm{z}$ različno starimi drevesi

$7,2 \mathrm{~m} \quad 13,1 \mathrm{~m}$

povprečna dvoetažna enodružinska hiša

grapa ali potok globine $4 \mathrm{~m}$

največje dovoljeno višinsko odstopanje DMR5 na poraščenem terenu

največje dovoljeno višinsko odstopanje DMR1 na poraščenem terenu

\begin{tabular}{rrr}
$50 \mathrm{~m}$ & $7,2 \mathrm{~m}$ & $13,1 \mathrm{~m}$ \\
$20 \mathrm{~m}$ & $2,9 \mathrm{~m}$ & $5,3 \mathrm{~m}$ \\
$10 \mathrm{~m}$ & $\mathbf{1 , 4} \mathbf{m}$ & $2,7 \mathrm{~m}$ \\
$6 \mathrm{~m}$ & $\mathbf{0 , 9} \mathbf{m}$ & $\mathbf{1 , 6} \mathbf{m}$ \\
$-4 \mathrm{~m}$ & $\mathbf{- 0 , 6 ~ \mathbf { ~ }}$ & $-\mathbf{1 , 1} \mathbf{~ m}$ \\
$9 \mathrm{~m}$ & $\mathbf{1 , 3} \mathbf{m}$ & $2,4 \mathrm{~m}$ \\
$3,6 \mathrm{~m}$ & $\mathbf{0 , 5} \mathbf{m}$ & $\mathbf{1 , 0} \mathbf{m}$ \\
\hline
\end{tabular}

Ker je s CAS 2015 zahtevan večji preklop med aeroposnetki, lahko pričakujemo tudi, da se bodo dimenzije osrednjega dela posnetka, ki se ga uporabi za izdelavo ortofota, zmanjšale.

Oglejmo si še primer izračuna, kako velik del osrednjega dela posnetka je še sprejemljiv, da ga preslikamo na ortofoto, ter ob tem navidezno zvrnjeni cerkveni zvoniki ne bodo presegli dovoljenega odstopanja ortofota. Ponovno si pomagamo z izrazom (2). Sedaj poznamo zvrnjenost $\Delta R=2,25 \mathrm{~m}$, višino objekta $\Delta Z=20 \mathrm{~m}$ in višino projekcijskega centra $Z_{0}$. Največja oddaljenost šivne linije od preslikave projekcijskega 
centra na ortofoto bi v tem primeru bila $471 \mathrm{~m}$. Torej bi bila največja širina dela ortofota, narejenega iz enega posnetka $942 \mathrm{~m}$. Ta vrednost predstavlja $80 \%$ obstoječe najožje širine ortofota narejenega iz enega posnetka.

\section{Položajna točnost ortofota narejenega $\mathrm{z}$ brezpilotnim letalnikom}

Za izdelavo ortofotov manjših območij, velikih do nekaj $\mathrm{km}^{2}$, se danes vse pogosteje uporablja brezpilotne letalnike (drone). Ti letijo na veliko nižjih višinah in omogočajo izdelavo ortofotov z zelo veliko prostorsko ločljivostjo. Dolžina talnega intervala oziroma en slikovni element v naravi lahko doseže tudi samo nekaj cm (Kosmatin Fras s sodelavci 2015). Sama položajna točnost pa je velikokrat slabša od prostorske ločljivosti in zelo neenotna na območju izdelave celotnega ortofota, saj je odvisna od števila posnetkov z zadovoljivim preklopom, ki prikazujejo nek del območja. Manjše število posnetkov oziroma nezadovoljiva točnost orientacije posnetkov prinese krajevne napake v izdelavi oblaka točk, narejenega na podlagi slikovnega ujemanja (image matching). Iz oblaka točk pred izdelavo odstranimo vse objekte, ki jih ne potrebujemo pri izdelavi ortofota na podlagi DMR. Zato na območjih z vegetacijo pridobimo oblak točk $\mathrm{z}$ manjšo gostoto ali na območju s stavbami ne dobimo nobene točke, kar pomeni, da je tudi interpolacija DMR na tem mestu otežena. Zato je za oceno točnosti DMR zelo priporočljivo izdelati karto gostote uporabljenega filtriranega oblaka točk za celotno območje izdelave ortofota (Kerin 2014). Z upoštevanjem teorema vzorčenja lahko izračunamo, katera gostota točk filtriranega oblaka točk je še zadovoljiva za izdelavo DMR zadovoljive ločljivosti za merilo, v katerem želimo izdelati ortofoto (Triglav Čekada 2011; Triglav Čekada in Zorn 2014). Enako kot pri uporabi državnih ortofotov pa je pred uporabo ortofota, narejenega z letalnikom, priporočljiva preverba položajne točnosti izdelka s pomočjo kontrolnih točk izmerjenih na terenu. Za izračun odstopanj na ortofotu, narejenem s pomočjo letalnika, tudi ne moremo prevzeti zgoraj omenjenih izrazov (poglavje 3.2), saj posnetki letalnikov večinoma ne izpolnjujejo osnovnega pogoja o skorajšnji vertikalnosti, pa tudi DMR nima enovite višinske točnosti.

\section{Sklep}

Kljub izboljšavi položajne točnosti državnega ortofota leta 2015, zaradi uvedbe bolj točnega lidarskega DMR1 v postopek njegove izdelave, pa na ortofotu še vedno lahko pričakujemo večja položajna odstopanja od predpisanih. Predvsem navidezna zvrnjenost višjih grajenih objektov, kot so stolpnice in zvoniki cerkva, občutno presega največja dovoljena položajna odstopanja na območjih blizu šivov med ortofoti. Prav tako je lahko gozdni rob ponekod preveč navidezno zvrnjen. Deloma bi ta odstopanja lahko rešili, v kolikor bi za izdelavo ortofota uporabili še manjši osrednji del posameznega posnetka, vendar kljub temu ne bi rešili problema vseh visokih stavb. Ta odstopanja bi lahko rešili le, če bi državni ortofoto postal pravi ortofoto, torej bi pri njegovi izdelavi uporabili DMP. Kljub temu pa visoke stavbe in gozdni rob niso največji problem ortofota, saj že na ortofotu samem vidimo, kako je streha navidezno zvrnjena in se ne pokriva s temelji stavbe, zato ta odstopanja pri 2R-zajemu na podlagi ortofota lahko upoštevamo. Večji problem predstavljajo ozke grape in večja odstopanja v visokogorju, ki se jih pri zajemu na podlagi ortofota niti ne zavedamo. Opazimo jih le, v kolikor podatke primerjamo z drugimi ortofoti ali drugimi bolj natančnimi podatki. Že majhna položajna napaka DMR-ja na navpičnih stenah visokogorja lahko pomeni velike višinske napake v DMR-ju in posledično velika položajna odstopanja ortofota. Ortofota zato nikoli ne smemo obravnavati kot položajno absolutno točenega vira; drugi sloji, ki jih na njem prikazujemo, so lahko bolj točni od njega. Predvsem sloji, ki so bili zajeti iz osnovnih virov, kot so stereoposnetki CAS ali oblak lidarskih točk, so lahko lokacijsko veliko bolj pravilni kot ortofoto. Seveda pa tudi ne moremo trditi, da je vsak vektorski sloj, ki ga prikažemo na ortofotu 
bolj položajno točen od ortofota. Tako na primer sloj zemljiškokatastrskega prikaza večinoma ni bolj točen od ortofota, saj je prikaz mej na njem le informativne narave in ni namenjen prenosu v naravo (Mivšek, Ravnihar in Žnidaršič 2012).

Kljub povedanemu, pa državnemu ortofotu vseeno ostaja primat na področju enostavne uporabe za fotointerpretacijo ter dobre časovne ločljivosti, saj dobimo vsake tri leta nove izdelke, ki pokrivajo celotno Slovenijo.

\section{Viri in literatura}

Bric, V., Berk, S., Oven, K., Triglav Čekada, M. 2015: Aerofotografiranje in aerolasersko skeniranje Slovenije. 20. srečanje Slovenskega združenja za geodezijo in geofiziko. Ljubljana.

Kerin, A. 2014. Uporaba posnetkov z brezpilotnega zračnega plovila za izdelavo digitalnega modela reliefa. Diplomsko delo, Fakulteta za gradbeništvo in geodezijo Univerze v Ljubljani. Ljubljana.

Kosmatin Fras, M. 2004: Vpliv kakovosti vhodnih podatkov na kakovost ortofota. Geodetski vestnik 48-2.

Kosmatin Fras, M., Drobne, S., Gregorič, H., Oven, J. 2006: Raziskava uporabe ortofota (DOF5) v praksi. Geodetski vestnik 50-2.

Kosmatin Fras, M., Fabiani, N., Triglav Čekada, M. 2014: Kakovost državnega ortofota v različnih letnikih njegove izdelave. Geodetski vestnik 58-4. DOI: 10.15292/geodetski-vestnik.2014.04.695-709

Kosmatin Fras, M., Valič, R., Bone, M., Mesarič, M. 2015: Uporaba malih brezpilotnih letalnikov za zajem prostorskih podatkov. Geodetska (r)evolucija: zbornik posveta 43. geodetskega dne. Ljubljana.

Kraus, K. 2004: Photogrammetry: Geometry from Images and Laser Scans. Berlin, New York.

Mivšek, E., Ravnihar, F., Žnidaršič, H. 2012: Izdelava zemljiškokatastrskega načrta. Geodetski vestnik 56-4. DOI: 10.15292/geodetski-vestnik.2012.04.691-697

Opis podatkovne zbirke ortofoto. Geodetska uprava Republike Slovenije. Medmrežje: http://www.e-prostor.gov.si/si/zbirke_prostorskih_podatkov/topografski_in_kartografski_podatki/ortofoto/ (5.6.2016).

Petrovič, D., Podobnikar, T., Grigillo, D., Kozmus Trajkovski, K., Vrečko, A., Urbančič, T., Kosmatin Fras, M. 2011: Kaj pa topografija? Stanje in kakovost topografskih podatkov v Sloveniji. Geodetski vestnik 55-2. DOI: 10.15292/geodetski-vestnik.2011.02.304-318

Pukelsheim, F. 1994: The three sigma rule. The American Statistician 48-2.

Razpisna dokumentacija za izvedbo Aeroposnetki in ortofoto 2009-2010. Geodetska uprava Republike Slovenije. Ljubljana, 2008.

Razpisna dokumentacija za izvedbo Cikličnega aerofotografiranja Slovenije 2012. Geodetska uprava Republike Slovenije. Ljubljana, 2011.

Razpisna dokumentacija za izvedbo Cikličnega aerofotografiranja Slovenije 2014. Geodetska uprava Republike Slovenije. Ljubljana, 2014.

Razpisna dokumentacija za izvedbo Cikličnega aerofotografiranja Slovenije 2015-2016. Geodetska uprava Republike Slovenije. Ljubljana, 2015.

Razpisna dokumentacija za izvedbo Cikličnega aerofotografiranja Slovenije 2016. Geodetska uprava Republike Slovenije. Ljubljana, 2016.

Triglav Čekada, M. 2011: Možnosti uporabe zračnega laserskega skeniranja (LIDAR) za geomorfološke študije. Geografski vestnik 83-2.

Triglav Čekada, M., Bric, V. 2015: Končan je projekt Laserskega skeniranja Slovenije. Geodetski vestnik 59-3.

Triglav Čekada, M., Tršan, S., Pegan-Žvokelj, B., Lukač, N., Bizjak, M., Brumen, M., Žalik, B. 2016: STEZA - stereozajem iz aerofotografij in podatkov lidar. Geodetski vestnik 60-2.

Triglav Čekada, M., Zorn, M. 2014: Ugotavljanje intenzivnosti geomorfnih procesov s pomočjo posnetkov cikličnega aerofotografiranja Slovenije. Geografski vestnik 86-2. DOI: http://dx.doi.org/10.3986/ GV86206 


\section{Summary: Radial displacement of objects on the national orthophoto or what we should know when using national orthophoto?}

(translated by the author)

The users of the national orthophoto of Slovenia often believe that this spatial source has no positional errors, and they also mix the values for the ground sampling distance (resolution) and those for the positional accuracy. This paper describes the production and main factors that affect the quality of the national orthophotos. It also deals in detail with the question why the objects presented on the national orthophoto have a radial displacement and how large radial displacements can be expected in different cases.

National orthophotos of Slovenia are created from the Cyclical Aerial Survey of Slovenia (CAS) images. The CAS started in 1975, while regular three-year cycles for covering the whole area of Slovenia were introduced in 1985. The first cycle of CAS in which orthophoto was produced for the whole country started in 1999. Afterwards, the orthophotos have been made in every cycle of CAS. The orthophotos are in the scale 1:5,000. Due to better quality of images and digital terrain model (DTM) used, the orthophoto positional accuracy has been improving with every cycle of CAS. A substantial progress in the positional accuracy of orthophotos was made in the year 2006, when the digital aerial camera was introduced in CAS, and photogrammetric DTM $5 \mathrm{~m} \times 5 \mathrm{~m}$ was made and applied for orthophoto production. These orthophotos had a ground sapling distance of $0.5 \mathrm{~m}$. In the year 2009 a new national coordinate system D96/TM, based on ETRS89, was introduced in aerotriangulation of the CAS images. In addition, a new orthophoto ground sampling distance of $0.25 \mathrm{~m}$ was introduced, with better results being achieved. In 2015 the national aerial laser scanning was completed, resulting in the new, more accurate DTM $1 \mathrm{~m} \times 1 \mathrm{~m}$. This DTM was introduced in the national orthophoto production already in 2015. The declared positional accuracy of the orthophoto is $1.0 \mathrm{~m}$ RMSE for those made between 2009 and 2014, when DTM $5 \mathrm{~m} \times 5 \mathrm{~m}$ was used for orthophoto production. The declared positional accuracy of $0.75 \mathrm{~m}$ RMSE is defined for orthophotos based on DTM $1 \mathrm{~m} \times 1 \mathrm{~m}$.

The national orthophoto is produced with DTM and therefore it is not a true orthophoto. This means that the objects that are situated above or below the DTM are presented on the orthophoto with a radial displacement. This radial displacement can be best seen on buildings, which seem like leaning on one side (Figure 5). The radial displacement also affects the tall cliffs in the mountains, but there it cannot be easily noticed.

The direction and size of the radial displacement of one object is not constant on orthophotos made in different years. It depends on the location of the projection centre and focal length of the aerial camera used, which change between different CAS. The radial displacement can exceed the positional accuracy of orthophotos, especially near the seam lines which connect two orthophoto-sections made from two images.

From the geometrical connection between the original image and the orthophoto (Figure 6) we can calculate the size of the radial displacement $\Delta R$, when we know the height of the object $\Delta Z$, the flying height $Z_{0}$ and the maximum half-length of orthophoto section diameter $R$. The radial displacement is:

$$
\Delta R=\frac{\Delta Z}{Z_{0}} \cdot R .
$$

We can calculate the flying height $Z_{0}$ by knowing the ground sampling distance $D T I$ and the pixel size $d$ of the original image and the focal length $f$ of the aerial camera applied:

$$
Z_{0}=\frac{D T I \cdot f}{d}
$$


We will insert in the upper equations the data from a real example of CAS 2014. The aerial camera used in the CAS 2014 was Vexcel UltraCam-XP. It has a pixel size $d$ of $6 \mathrm{~mm}$, a focal length $f$ of $100.500 \mathrm{~mm}$ and a ground sampling distance $D T I$ of $0.25 \mathrm{~m}$. From these data we get the flying height $Z_{0}$ of $4,190 \mathrm{~m}$. The average size of orthophoto-section in the 2014 orthophoto production can be derived from presentation or visualization of vector seem lines (Figure 4), which connect different orthophoto-sections in one orthophoto. The average maximum half-length of the orthophoto-section diameter $R$ in the longest direction is $1,100 \mathrm{~m}$ and in the shortest $600 \mathrm{~m}$. We can easily calculate the radial displacement of a tall object in the orthophoto by defining how high above or below the DTM this object is. In Table 2 the values of radial displacement $\Delta R$ for the following examples are presented (from top to bottom): rocky cliffs $50 \mathrm{~m}$ high, church bell tower $20 \mathrm{~m}$ high, forest edge $10 \mathrm{~m}$ high, average two-floor house $6 \mathrm{~m}$ high, ravine or creek $4 \mathrm{~m}$ deep under DTM, the maximum allowed height error for DTM $5 \mathrm{~m} \times 5 \mathrm{~m}$ (equals $9 \mathrm{~m}$ ) and the maximum allowed height error for DTM $1 \mathrm{~m} \times 1 \mathrm{~m}$ (equals $3.6 \mathrm{~m}$ ). We conclude that the most problematic radial displacements, which can exceed the allowed positional error of the orthophoto are those caused by high rocky cliffs (maximal $\Delta R$ is $13.1 \mathrm{~m}$ ) and church bell towers (maximal $\Delta R$ is $5.3 \mathrm{~m}$ ) which are located near seam lines of an orthophoto. The radial displacement of church bell towers or other high buildings can easily be seen on orthophoto and therefore not used for example in the 2Ddigitalisation of urbanization change. The radial displacement of rocky cliffs on the other hand cannot be seen on orthophoto and therefore can cause problems when making for example the 2D-digitalisation of vegetation change in mountainous areas. The radial displacement of buildings could in the future be solved by production of a true orthophoto. The radial displacement of tall vertical cliffs in mountains cannot be solved, as a small positional error of DTM (for example $0.5 \mathrm{~m}$ in location) can result in a large height error of DTM and consequently a big radial displacement of the orthophoto.

Therefore, the users of the Slovenian national orthophoto should be aware that different objects can be presented of the orthophoto with different radial displacements, which in some cases may exceed the allowed positional accuracy of the orthophoto. Special caution should be applied when digitalizing objects in high and steep mountains. It is recommended that another source for digitalization is used in such problematic areas, for example aerial laser scanning data or photogrammetric stereorestitution from the original CAS images. 
